\title{
ANALISA SISTEM INFORMASI PENGELOLAAN KEUANGAN PADA UPT DINAS PENDIDIKAN KECAMATAN NEGLASARI KOTA TANGERANG
}

\author{
Sri Rahayu ${ }^{1}$ \\ Ai Ratna Sari ${ }^{2}$ \\ Tri Sendra Saputra ${ }^{3}$ \\ Dosen STMIK Raharja Informatika ${ }^{1}$, STMIK Raharja jurusan Sistem Informasi ${ }^{2}$, \\ STMIK Raharja Jurusan Sistem Informasi ${ }^{3}$ \\ Jl. Jendral Sudirman No. 40, Modernland, Tangerang \\ Email :srirahayu@raharja.info,ai.ratna@raharja.info,tri.sendra@raharja.info
}

\begin{abstract}
ABSTRAK
Dalam era globalisasi yang semakin pesat, pengelolaan keuangan merupakan penyajian informasi yang digunakan oleh suatu instansi tentang perkembangan keuangannya.UPT Dinas Penddikan Kecamatan Neglasari Kota Tangerang adalah sebuah instansi yang bergerak di bidang pendidikan. Pada kantor UPT Dinas Pendidikan Kecamatan Neglasari Kota Tangerang ini sistem pengelolaan keuangan yang sedang berjalan masih belum terkomputerisasi. Penelitian yang berjudul Analisa Sistem Pengelolaan Keuangan pada UPT Dinas Pendidikan Kecamatan Neglasari Kota Tangerang dengan metode penelitian yang dilakukan yaitu dengan cara observasi, wawancara dan studi pustaka ini menguraikan masalah yang pertama pengelolaan keuangan yang berjalan pada saat ini yaitu dengan cara mencatat data masukan, data keluaran, serta membuat laporan keuangan masih dilakukan secara satu persatu yang mengakibatkan kurangnya keakuratan, yang kedua Penyusunan laporan pengelolaan keuangan yang berjalan pada saat ini yaitu dengan cara membuat laporan keuangan pada Microsoft Excel berdasarkan file laporan dari sekolah - sekolah, laporan dari guru dan file laporan dari kantor, karena banyak nya jumlah file yang yang diterima oleh bagian keuangan maka dalam pembuatan laporan keuangannya menjadi tidak tepat waktu. Dengan demikian, adanya kebutuhan informasi yang semakin lama semakin meningkat, maka diperlukan sistem yang dapat membantu proses pengelolaan dan pembuatan laporan keuangan agar dapat menghemat waktu dan pengeluaran biaya pembangunan sistem dengan menggunakan website berbasis xampp sebagai wab servernya MySQL sebagai Database Managemen dan PHP sebagai bahasa script.
\end{abstract}

Kata kunci : pengelolaan keuangan, sistem informasi

\section{ABSTRACT}

In the era of rapid globalization, financial management is the presentation of information used by an agency about the financial development.UPT District Education Service District Neglasari Tangerang is an agency engaged in the field of education. At the office of UPT Education Office District Neglasari Tangerang City is ongoing financial management system is still not computerized. The research entitled Analysis of Financial Management System at UPT Education Office of Neglasari Subdistrict of Tangerang City with research method that is done by observation, interview and literature study describes the first problem of current financial management that is by recording input data, output data, And make the financial statements are still done one by one that resulted in lack of accuracy, the second Preparation of financial management reports that run at this time is by making financial statements in Microsoft Excel based on report files from schools, reports from teachers and file reports from Office, because many of its number of files received by the finance 
department in the making of its financial statements to be not on time. Thus, the need for information is increasingly longer, then needed a system that can help the process of management and making of financial statements in order to save time and expenditure cost of system development using xamppbased website as wab server MySQL as database management system and PHP scripting language.

Keywords: financial management, systeminformation

\section{PENDAHULUAN}

Tuntutan terhadap pengelolaan keuangan secara baik merupakan issue utama yang harus dilakukan pemerintah daerah dalam meciptakan pengelolaan keuangan yang baik.Dimana pengelolaan keuangan yang baik adalah kemampuan mengatur keuangan secara ekonomis,efesien dan akuntable

Unit Pelaksana Teknis (UPT) Dinas Pendidikan Kecamatan Neglasari Kota Tangerang adalah unit pelaksana yang ada di Dinas Pendidikan Provinsi Banten.Sesuai dengan tugas pokok dan fungsinya UPT Dinas Pendidikan Kecamatan Neglasari Kota Tangerang harus merancang dan membuat program kerja - program kerja sesuai dengan ketentuan yang berlaku.

Beberapa kesulitan yang dialami UPT Dinas Pendidikan Kecamatan Neglasari Kota Tangerang adalah dalam pengelolaan keuangan.Masalah yang terjadi pada umumnya terletak pada tata cara pengelolaan keuangan yang masih menerapkan cara - cara konvesional.Solusi yang ditawarkan untuk mengatasi masalah tersebut adalah dengan membangun Sistem Informasi Pengelolaan Keuangan yang dapat digunakan dalam pengelolaan keuangan serta sampai pembuatan laporan keuangan.

Berawal dari uraian permasalahan diatas maka menarik untuk dibuatnya suatu sistem informasi pengelolaan keuangan disuatu lembaga pendidikan yang diimplemetasikan dalam1 bentuk perangkat lunak yang sudah terkomputerisasi ,maka jurnal ini mengambil topik "ANALISA SISTEM INFORMASI PENGELOLAAN KEUANGAN PADA UPT DINAS PENDIDIKAN KECAMATAN NEGLASARI KOTA TANGERANG”.

\section{PERMASALAHAN}

Berdasarkan latar belakang masalah yang diuraikan diatas, terdapat permasalahan yang terjadi yaitu Sistem pengelolaan keuangan yang berjalan pada saat ini yaitu dengan cara mencatat data masukan, data keluaran, serta membuat laporan keuangan masih dilakukan secara satu persatu yang mengakibatkan kurangnya keakuratan dan juga mengakibatkan waktu yang tidak efektif dan efesien.

\section{METODE PENELITIAN}

Metode penelitian yang dilakukan dalam penelitian ini adalah mengumpulkan data mengenai keadaan secara langsung untuk mendapatkan data secara relevan. Teknik pengumpulan data yang digunakan untuk mencari ataupun mengumpulkan data serta mengolah informasi yang diperlukan yaitu:

1. Metode observasi

Merupakan pengumpulan data dengan observasi langsung atau dengan mengamati langsung dan melakukan pencatatan terhadap beberapa objek penelitian dari beberapa individu yang bersangkutan pada UPT Dinas Pendidikan Kecamatan Neglasari Kota Tangerang. 
2. Metode wawancara

Merupakan mengadakan wawancara langsung untuk memperoleh keterangan dengan cara tanya jawab,sambil bertatap muka antara penanya dan pewawancaratentang bagaimana prosedur pengelolaan keuangan yang terjadi saat ini pada UPT Dinas Pendidikan Kota Tangerang.

3. Memetode studi pustaka.

Merupakan metode pengumpulan data yang diarahkan pada pencarian data dan informasi berdasarkan melalui dokumen tertulis seperti buku, majalah, jurnal, internet, artikel dan lain sebagainya yang berhubungan dengan penelitian sebagai bahan referensi salam penyusunan laporan.

\section{METODE PERANCANGAN}

Dalam metode perancangan yang digunakan penulis yaitu menggunakan rancangan protoype untuk perancangan sedangkan xampp sebagai wab servernya $M y S Q L$ sebagai Database Managemen dan PHP sebagai bahasa script.

\section{LANDASAN TEORI}

\section{Pengertian Sistem}

Menurut Fat dalam buku Konsep Sistem Informasi oleh Jeperson Hutahaean (2014: 1) Sistem adalah suatu himpunan suatu "benda" nyata atau abstrak (a set of things) yang terdiri dari bagian-bagian atau komponen-komponen yang saling berkaitan, berhubungan, berketergantungan, saling mendukung yang secara keseluruhan bersatu dalam satu kesatuan (Unity) untuk mencapai tujuan tertentu secara efesien dan efektif.

\section{Pengertian Informasi}

Menurut Gorden B Davis dalam buku Konsep Sistem Informasi Oleh Jeperson Hutahean (2014: 9) "Informasi adalah data yang telah diolah menjadi suatu bentuk yang penting bagi si penerima dan mempunyai nilai nyata atau yang dapat dirasakan dalam keputusan-keputusan yang sekarang atau keputusan - keputusan yang akan datang".

\section{Pengertian Sistem Informasi}

Sistem Informasi merupakan elemen- elemen yang saling berinteraksi secara sistematis dan teratur untuk menciptakan dan membentuk aliran informasi yang akan mendukung pembuatan keputusan dan melakukan kontrol terhadap jalannya perusahaan.

\section{Pengertian Keuangan}

Menurut KBBI ( 2012:1767 ) diartikan keuangan adalah segala sesuatu yang bertalian dengan uang,seluk beluk uang,urusan uang, keadaan uang. 


\section{Pengertian Pengelolaan Keuangan}

Pengelolaan keuangan adalah segala bentuk kegiatan administratif yang dilakukan dalam bentuk beberapa tahapanyang meliputi : perencanaan, penyimpanan, penggunaan , pencatatan serta pengawasan yang kemudian di akhiri dengan pertanggung jawaban (pelaporan) terhadap siklus keluar masuknya dana / uang dalam sebuah instansi pada kurun waktu tertentu.

\section{Pengertian PHP}

Menurut Supono dalam bukunya "Pemrograman Web dengan menggunakan PHP dan Framework codeigniter" ( $2016: 3$ ) PHP adalah suatu bahasa pemrograman yang digunakan untuk menerjemahkan baris kode program menjadi kode mesin yang dapat dimengerti oleh komputer yang bersifat server - side yang dapat ditambahkan kedalam HTML

\section{Pengertian MySQL}

Menurut Sutarman (2003) pengertian MySQL adalah sebuah program database yang mampu menerima dan mengirimkan datanya dengan sangat cepat, multi user, serta menggunakan perintah standar SQL ( Structured Query Language ).

\section{LITERATURE REVIEW}

Dalam upaya mengembangkan dan menyempurnakan pengembangan ini perlu dilakukan Study Pustaka (Literature Review) sebagai salah satu dari penerapan metode penelitian yang dilakukan, diantaranya sebagai berikut:

1. Penelitian yang dilakukan oleh Fico Ristiandana [2012]. Penelitian yang telah dilakukan oleh Fico Ristiandana berjudul "Analisa Sistem Laporan Keuangan Secara Online Pada Bagian Keuangan dan Perencanaan Sekretariat Daerah Kabupaten Tangerang" pada tahun 2012" pembahasan ini hanya dibatasi pada laporan keuangan pada bagian keuangan dan perencanaan. Mulai dari bagaimana proses laporan keuangan dapat berjalan menggunakan suatu aplikasi yang dapat memudahkan dalam mengolah data-data laporan keuangan hingga mempercepat proses penyampaian laporan dan bagaimana membuuat suatu usulan sistem laporan keuangan dengan menggunakan aplikasi yang memudahkan dalam melakukan proses laporan keuangan hingga sistem dapat diimplementasikan secara efektif dan efisien dalam pembuatan laporan.

2. Penelitian yang dilakukan oleh Pemi Lusiana [ 2008 ].Penelitian yang telah dilakukan berjudul “Sistem Informasi Pengelolaan Keuangan di Kantor Kecamatan Cipaku Kabupaten Ciamis " pada tahun 2008.Pembahasan ini hanya membahas mengenai proses pembuatan SPP, SPM, SPJ dan pembuatan laporan.

3. Penelitian yang dilakukan oleh Kuncoro Thesaurianto di Semarang . Penelitian yang telah dilakukan berjudul " Analisis Pengelolaan Keuangan Daerah Terhadap Kemandirian Daerah " Pembahasan ini membahas mengenai faktor - faktor yang berpengaruh dalam penerimaan PAD Pro Jawa Tengah.

4. Penelitian Skripsi yang dilakukan oleh Rini Istiana di STMIK Raharja.Penelitian ini berjudul " Perancangan Sistem Informasi Laporan Keuangan Pada Kantor Kecamatan Batu Ceper Kota Tangerang “.Dalam Penelitian terdapat kesimpulan bahwa pada Kantor Kecamatan Batuceper Kota Tangerang dalam pengolahan data laporan keuangan ini belum terkomputerisasi, perhitungan jurnal transaksi yang manual, 
proses pengolahan data belum rapih . Maka dari itu diciptakan suatu rancangan yang dimulai dari pembuatan diagram, desai dari sistem berbasis web dengan menggunakan software ( perangkat lunak ) Dreamwever CS5, Php Myadmin, dan Appserv.

5. Penelitian yang di lakukan oleh Tri Sutrisno [ 2012 ].dalam penelitiannya yang berjudul " Aplikasi Sistem Keuangan Pada PT.Cendana Pilar Utama Berbasis Web ". Pembahasan ini Hanya di Batasi pada pembuatan aplikasi aplikasi sistem keuangan Pada PT.Cendana Pilar Utama, mulai dari penginputan data karyawan, penginputan data nama rekening dan pembuatan laporan keuangan secara perodik pada sistem ini terletak pada pembuatan sistem yang dibuat mendetail.

\section{ANALISIS SISTEM}

Analisis sistem merupakan penguraian sistem informasi yang sedang berjalan secara utuhkedalam bagian - bagian komponennya dengan maksud untuk mengidentifikasi dan mengevaluasi permaslahan - permasalahan, hambatan - hambatan yang terjadi dan kebutuhan yang diharapkan sehinggah dapat diusulkan kebaikan - kebaikannya dalam sistem ini

\section{ANALISIS MASALAH}

Sistem Penyusunan laporan pengelolaan keuangan yang berjalan pada saat ini yaitu dengan cara membuat laporan keuangan pada Microsoft Excel berdasarkan file laporan dari sekolah - sekolah, laporan dari guru dan file laporan dari kantor, karena banyak nya jumlah file yang yang diterima oleh bagian keuangan proses pencatatan laporan keuangan sering terjadi kekeliruan yang ada pada data - data dalam laporan pengelolaan keuangan dankeakurata laporan keuangannya masih dikatakan kurang akurat.

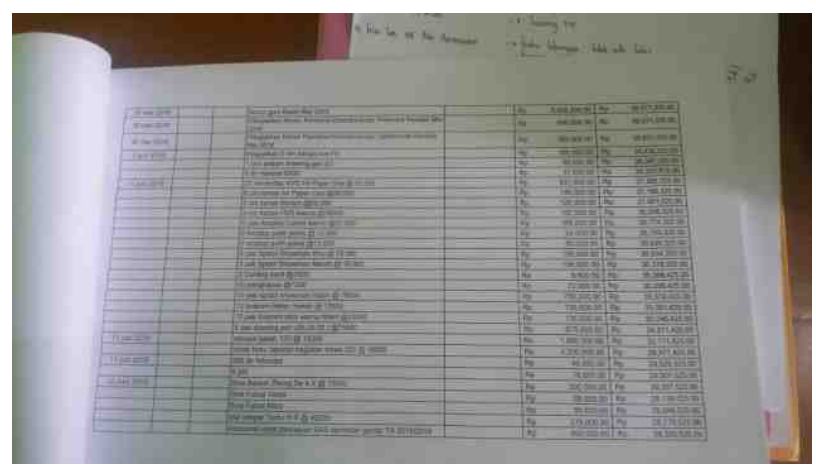

Gambar 1 . Laporan Keuangan

\section{PEMECAHAN MASALAH}

Karena cara mencatat data masukan, data keluaran, serta membuat laporan keuangan masih dilakukan secara satu persatu yang mengakibatkan kurangnya keakuratan , yang kedua Penyusunan laporan pengelolaan keuangan yang berjalan pada saat ini yaitu dengan cara membuat laporan keuangan pada Microsoft Excel berdasarkan file laporan dari sekolah sekolah, laporan dari guru dan file laporan dari kantor, karena banyak nya jumlah file yang yang diterima oleh bagian keuangan maka dalam pembuatan laporan keuangannya menjadi tidak tepat waktu .Untuk mengatasi masalah yang ada pada masalah diatas, maka diperlukan beberapa alternatif pemecahan dari permasalahan yang dihadapi, antara lain :

1. Membuat sistem yang terkomputerisasi untuk sistem pencatatan data masukan, dara keluaran serta laporan pengelolaan keuangan agar saling terintegrasi satu sama lain 
karena data yang terintegrasi satu sama lain akan membuat laporan keuangn menjadi mudah, akurat dan tepat waktu.

2. Membuat rancangan sistem yang dibutuhkan oleh user dengan aplikasi visual serta Menerapkan perancangan sistem informasi komputerisasi tersebut pada UPT Dinas Pendidikan Kota Tangerang, sehingga dapat digunakan oleh bendahara dan seluruh pihak yang dirasa berwenang untuk menjalankan sistem di UPT Dinas Pendidikan Kecamatan Neglasari Kota Tangerang.

\section{IMPLEMENTASI}

Rancangan sistem berupaya menganalisa data masukan, data keluaran, memproses data, menyimpan data, dan menghasilkan informasi. Perancangan sistem digunakan untuk menganalisa, merancang, dan mengimplementasikan peningkatan fungsi yang bisa dicapai melalui penggunaan sistem informasi terkompoterisasi.

\section{Tampilan Program}

\section{Tampilan Login}

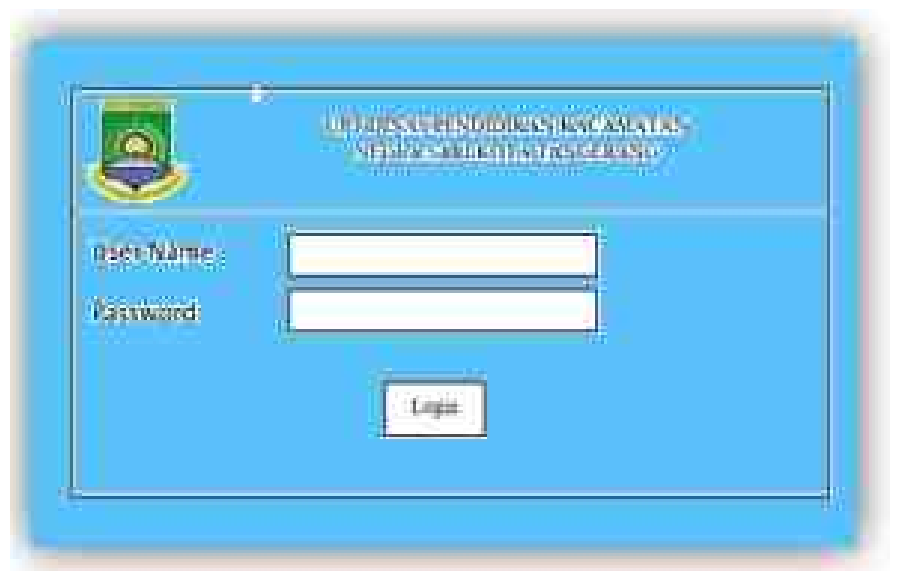

\section{Gambar 1. Tampilan Login}

Pada Gambar 1 menjelaskan halaman Login seorang bendahara untuk melakkan pengelolaan keuangan. Login username diisi nama user yang telah ada di MySQL, password diisi dengan password user, tombol login digunakan untuk masuk ke menu admin.

\section{Menu Home}

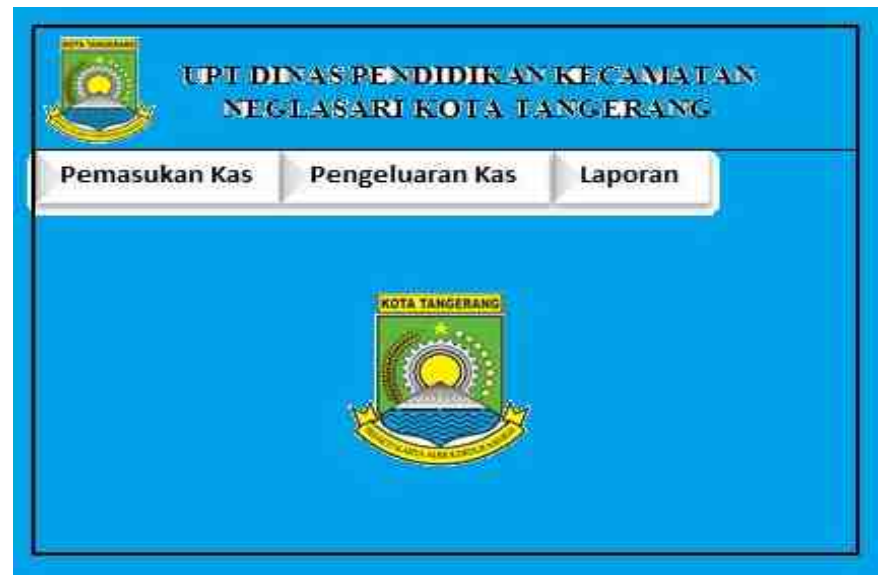

Gambar 2 . Menu Home 
Pada gambar 2 menjelaskan menu home setelah melakukan login untuk melakukan proses pengelolaan keuangan .

\section{Tampilan Pemasukan Kas}

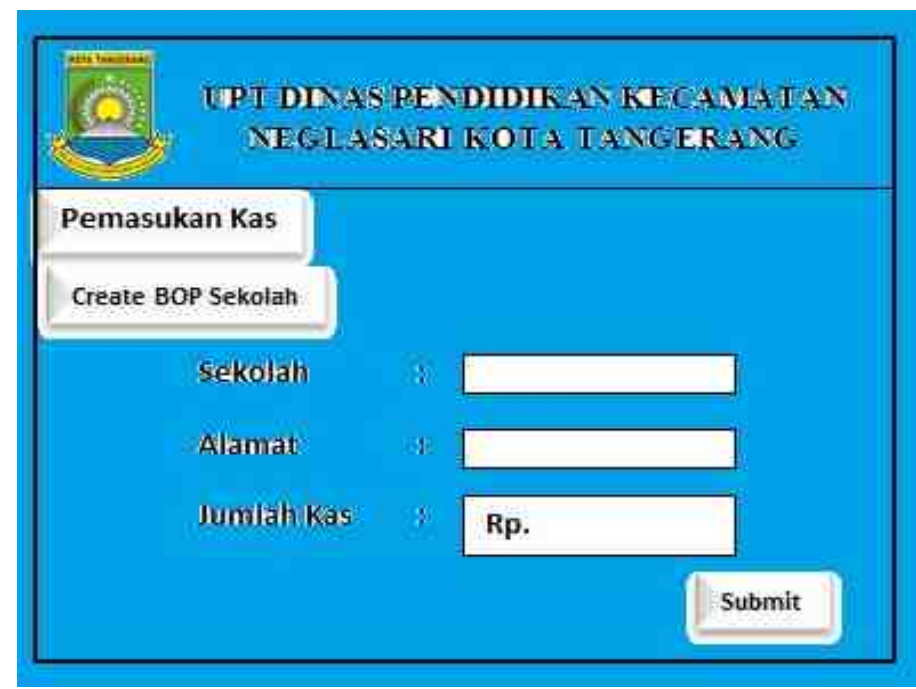

Gambar 3. Tampilan Pemasukan Kas

Pada gambar 3 menjelaskan halaman Pemasukan KAS dan didalam menu pemasukan KAS terdapat data yang harus diinput setelah itu di submit untuk menjadi laporan.

\section{Tampilan Pengeluaran Kas}

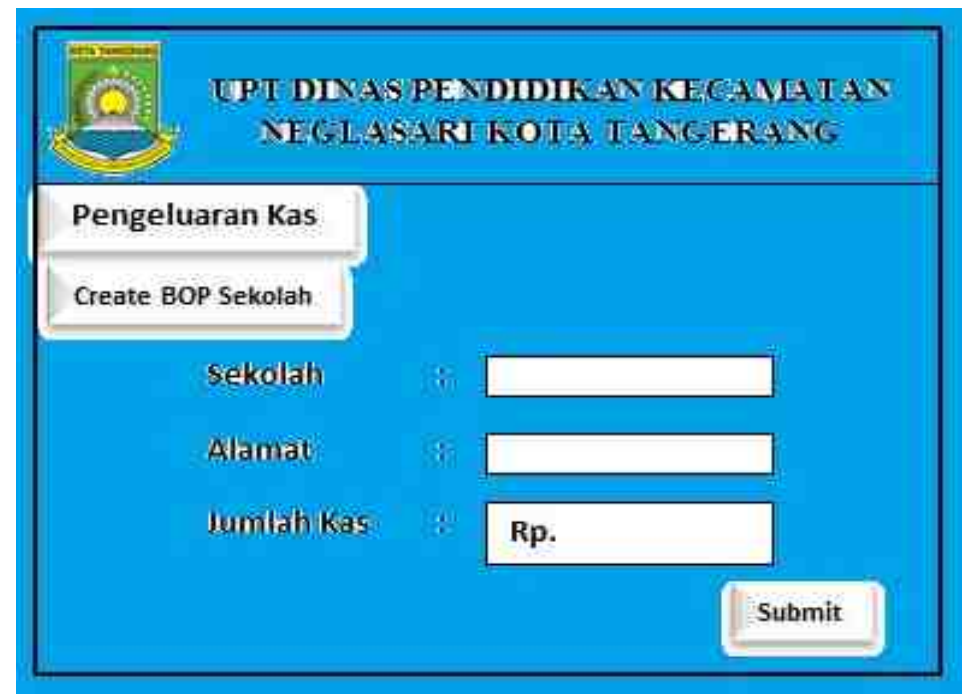

Gambar 4.Tampilan Pengeluaran Kas

Pada gambar 4 menjelaskan tentang tampilan pengeluaran kas BOP Sekloah dimana terdapat data yang harus diinput di dalam Database dan tampil pada menu ini. 


\section{KESIMPULAN}

Kesimpulan yang dapat diambil dari penelitian ini adalah membuat sistem informasi pengelolaan keuangan dalam hal penyimpanan data dan laporan menggunakan sistem yang terkomputerisasi dengan adanya sistem informasi pengelolaan keuangan ini dapat diharapkan ada upaya pengembangan lanjut menjadi aplikasi sistem informasi pengelolaan keuangan yang lebih sempurna dan melakukan perubahan sistem pengolahan data yang masih manual menjadi terkomputerisasi agar lebih efektif dan efisien serta membuat sistem yang memudahkan pembuatan laporan pengelolaan keuangan sehingga tidak terjadi kesalahan dan bisa menghasilkan laporan yang cepat dan akurat.

\section{DAFTAR PUSTAKA}

[1] Hutahean, Japerson. 2014. Konsep Sistem Informasi. Yogyakarta: CV Budi Utama.

[2] Pusat Bahasa Depdiknas:2012, Kamus Bahasa Indonesia. Jakarta.

[3] Supono. 2016. Pemrograman Web dengan menggunakan PHP dan Framework codeigniter. Yogyakarta: Deepublish.

[4] Sutarman, Sutarman.2003, "Membangun Aplikasi Wab Dengan PHP dan MySQL". Graha Ilmu, Jakarta.

[5] Lusiana, Pemi . 2008 .Sistem Informasi Pengelolaan Keuangan di Kantor Kecamatan Cipaku Kabupaten Ciamis. Ciamis.

[6] Ristianda, Fico . 2012 .Analisa Sistem Laporan Keuangan Secara Online Pada Bagian Keuangan dan Perencanaan Sekretariat Daerah Kabupaten Tangerang . Tangerang

[7] Sutrisno, Tri. 2012. Aplikasi Sistem Keuangan Pada PT.Cendana Pilar Utama Berbasis Web. Bogor. 